International Journal of Agriculture, Environment and Bioresearch

Vol. 4, No. 03; 2019

ISSN: $2456-8643$

\title{
EFFECTS OF NPK FERTILIZATION RATES ON CROP PRODUCTION AND PHOTOSYNTHETIC PERFORMANCE IN POTATO (SOLANUM TUBEROSUM L.)
}

\author{
Khaoula Mokrani*, Khawla Hamdi and Neji Tarchoun \\ Vegetable laboratory, Horticultural Department - Higher Agronomic Institute of Chott Meriem, University of \\ Sousse, 4042 Chott Meriem, Tunisia
}

http://doi.org/10.35410/IJAEB.2019.202222

\begin{abstract}
A pot experiment was conducted to study the influence of NPK fertilization levels on photosynthesis, soluble sugars content in source, phloem and sink organs and yield. The major plant nutrients NPK are involved in numerous physiological processes and their deficiency can reduce the yield of potato crop. This study aimed to investigate the response of two potato cultivars to different NPK regimes during subsequent stages, namely reduced photosynthesis capacity, disturbed sugars content and yield depression.

Our results showed that cultivar, NPK level and tuberization stage influence potato yield mainly through affecting sugars accumulation and distribution via the photosynthetic efficiency.

Data clearly demonstrated that Spunta, mid-early cultivar, showed higher performance concerning photosynthesis and yield under sufficient and deficient NPK fertilization levels. Plants subjected to excess NPK doses recorded an early defoliation. Daifla, mid-late cultivar, presented similar $\mathrm{Fv} / \mathrm{Fm}$ for all treatments during different dates of measure, while performing better regarding production parameters under excess NPK regimes.

Correlation test suggests that plant with high photosynthesis performance lead to low tuber yield under all NPK levels. This unexpected result could be explained by the effect of high temperature and long photoperiod which results in a decrease in tuber yield and an increase in photosynthesis.
\end{abstract}

Keywords: Fertilizer, Potato (Solanum tuberoum L.), Photosynthesis, Yield.

\section{INTRODUCTION}

Temperature and photoperiod conditions influence potato plant growth and development and affect directly the potential of the crop productivity, regulating its transpiration, photosynthesis and respiration processes in such a way as to control the growth and development of the plants throughout their physiological mechanisms [1]. With high temperatures conditions, the effect of nitrogen on the growth habit is more pronounced than with lower temperatures [2].

Nutrient deficiencies may limit the leaf canopy growth which results in a reduction in carbohydrate production and tuber growth [3]. In general, increasing $N$ fertilizers levels in 
potato crops result in reach high tuber yield than those with lower $\mathrm{N}$ supply. Nitrogen is the most needed nutrient for potato plant, then $\mathrm{N}$ availability leads to higher growth performance [4].

The effect of nitrogen could be seen in leaf area, chlorophyll content in leaf, size of tuber and specially time of tuber bulking [5, 6]. Photosynthesis is affected by nitrogen nutrition [7- 8, 9]. It was also found that as the nitrogen content decreased, the internal $\mathrm{CO} 2$ concentration was kept at a fairly constant level and the stomatal resistance increased [10]. The major impact of low nitrogen fertilization is a reducing tuber size due to a limited leaf area and an earlier defoliation, so a limited photosynthesis. Higher $\mathrm{N}$ levels are associated with important vegetative growth which promote photosynthetic efficiency, and hence more photoassimilats translocatation to storage organs [11].

It was demonstrated that with low fertilizers rates (NPK), the stem end of the tuber accumulate a lot of reducing sugars, then increasing $\mathrm{N}$ doses could result in an increase or decrease of reducing sugars in the apical end and also the stem end respectively. In general, high nitrogen rates reduce the amount of reducing sugars in potatoes tubers and lead to more sucrose and gave place to a potential conversion into starch [12].

A number of studies have shown that $\mathrm{Chl}$ fluorescence is a good indicator of nutrient deficiency [13]. The studies have focused on nitrogen $(\mathrm{N})$ because it is the macronutrient needed in the largest amount for plant development. Actually, most of the $\mathrm{N}(50-80 \%)$ in the leaf has a role in photosynthesis [14]. This finding are in agreement with those reported by Heisel et al. [15] when studying maize plant gown under different fertilization regimes of $\mathrm{N}, \mathrm{Mg}, \mathrm{An}$ and $\mathrm{Fe}$. Change in those elements rates lead to a remarkable decrease of fluorescence [15].

The aim of this study was to examine whether application of N, P2O5 and K2O in practically relevant amounts is as efficient as resupply in alleviating adverse effects of NPK deficiency in potato, namely low photosynthesis rate, disturbed total sugars amounts and yield reduction. A pot experiment with three distinct experimental groups was conducted in the greenhouse at the beginning and then in an open area next to the greenhouse and photosynthesis rate, Fluorometer values, yield as well as total sugars amounts in different organs were determined.

\section{MATERIALS AND METHODS}

\section{Growth conditions, plant materials and NPK treatments}

The pot experience of multi-factorial type, with plots subdivided, was done in the greenhouse of the Higher Agronomic Institute of Chott Mariam, Tunisia until 32 DAP (Day after Planting), and then pots have been moved to an open area next to the greenhouse. The aim of the current experiment was to study effects of basic fertilization with different NPK doses and reports on the photosynthesis efficiency, total sugars content in different organs as well as production parameters on high temperature and long photoperiod conditions for two potato cultivars, Spunta and Daifla. The substrate used in the experiment was a commercial substrate. 
Its $\mathrm{pH}$ value was 7.7 , respectively organic matter, carbon, clay, loam (Silt) and sand contents were 33.87, 38.27, 27.19 and 27, $19 \%$, N content was $11.31 \mathrm{~g} / \mathrm{kg}, \mathrm{P} 2 \mathrm{O} 5$ and $\mathrm{K} 2 \mathrm{O}$ amounts were respectively 0.24 and $0.18 \mathrm{mg} / \mathrm{kg}$.

One seed tuber was planted per pot, and the pots were placed in an open area next to the greenhouse after $32 \mathrm{DAP}$, natural rainfall was excluded using a transparent precipitation shelter.

The study, Mars to June 2017, aimed the photosynthesis efficiency, yield and total sugars accumulation in different organs (leaves, stems and tubers). At 24 DAP (stolon initiation), observation consisted of chlorophyll fluorescence parameters using fluorometer. During 30 DAP (tuber initiation) we collected data of fluorescence and total sugars content in adult leaves. From 49 to 78 DAP correspond respectively to tuber bulking, tuber filling and maturation, data was measured for photosynthesis, total sugars in leaves, stems and tubers and tuber yield per plant including tuber weight and number;

Five dates of the measure were made for each variant of chlorophyll fluorescence, starting with the 24th-day post potato plantation to 78 DAP.

Weather conditions under the greenhouse and the open area are given in table 1 and 2.

The treatment consisted 3 nitrogen, potassium and phosphorus levels (Table 3). The three NPK levels were designated as optimum or sufficient (doses were determined as recommended by the Technical Center of Potato and Artichoc, Tunisia, TCPA), deficient (- 25\% of the crop needs), and excess ( $+25 \%$ exceeding crop needs).

Application times of fertilizers were also done refer to the CTPA calender. More details of NPK treatments are shown in table 3.The statistical analysis of different data, was provided by XLSTAT, 2014, according to randomized complete block design (RCBD) with three replications. Data for studied character were recorded for each cultivar and fertilization at different growth stages and subjected then analysed using three-way analysis of variance (ANOVA). Correlation test was also calculated using XLSTAT.

Table 1. Mean values of temperature and photoperiod in greenhouse during the first 32 DAP (Day After Planting)

\begin{tabular}{ll}
\hline Meteorological Factor & Mean value during 32 days \\
\hline Average maximum greenhouse temperature $\left(\mathrm{C}^{\circ}\right)$ & $25.21^{\circ} \mathrm{C}$ \\
Average day hours (Hours: minutes) & $12: 36$
\end{tabular}

Table 2. Mean values of temperature and photoperiod in experiment period from 33 to 90 DAP (Day After Planting) 
International Journal of Agriculture, Environment and Bioresearch

Vol. 4, No. 03; 2019

ISSN: $2456-8643$

\begin{tabular}{|c|c|c|c|}
\hline Meteorological Factor & Month & & \\
\hline & April & May & June \\
\hline $\begin{array}{l}\text { Average minimum } \\
\text { temperature }\left(\mathrm{C}^{\circ}\right)\end{array}$ & 13.61 & 18.06 & 21.4 \\
\hline $\begin{array}{l}\text { Average maximum air } \\
\text { temperature }\left(\mathrm{C}^{\circ}\right)\end{array}$ & 22.10 & 27.03 & 34.4 \\
\hline $\begin{array}{l}\text { Average day hours (Hours: } \\
\text { minutes) }\end{array}$ & 13: 04 & 14: 01 & $14: 30$ \\
\hline
\end{tabular}

Table 3. Doses and application times of NPK per treatment

\begin{tabular}{|c|c|c|c|}
\hline Growth stage & Nitrogen N (g/pot) & $\begin{array}{l}\text { Phosphorus } \\
\text { (ml/pot) }\end{array}$ & Potassium $\mathrm{K}_{2} \mathrm{O}$ (g/pot) \\
\hline & $\begin{array}{l}\text { Deficient nitrogen }(1.809 \\
\text { added to soil) }\end{array}$ & $\begin{array}{l}\text { Deficient phosphorus } \\
(0.378 \\
\text { added to soil) }\end{array}$ & $\begin{array}{l}\text { Deficient potassium } \\
\text { (1.224 added to soil) }\end{array}$ \\
\hline \multirow[t]{3}{*}{$\begin{array}{l}\text { Vegetative growth } \\
\text { stage }\end{array}$} & $\begin{array}{l}\text { Sufficient nitrogen } \\
\text { added to soil) }\end{array}$ & $\begin{array}{l}\text { Sufficient phosphorus } \\
\text { ( } 0.561 \text { added to soil) }\end{array}$ & $\begin{array}{l}\text { Sufficient potassium } \\
\text { (1.632 added to soil) }\end{array}$ \\
\hline & $\begin{array}{l}\text { Excess nitrogen } \\
\text { added to soil) }\end{array}$ & $\begin{array}{l}\text { Excess phosphorus } \\
(0.702 \text { added to soil })\end{array}$ & $\begin{array}{l}\text { Excess potassium }(2.040 \\
\text { added to soil) }\end{array}$ \\
\hline & $\begin{array}{l}\text { Deficient nitrogen ( } \\
0.603 \text { added to soil) }\end{array}$ & $\begin{array}{l}\text { Deficient nitrogen }(0.210 \\
\text { added to soil })\end{array}$ & $\begin{array}{l}\text { Deficient potassium } \\
(0.612 \text { added to soil })\end{array}$ \\
\hline \multirow[t]{3}{*}{$\begin{array}{l}\text { Tuber initiation } \\
\text { stage }\end{array}$} & $\begin{array}{l}\begin{array}{l}\text { Sufficient nitrogen } \\
\text { added to soil })\end{array}\end{array}$ & $\begin{array}{l}\text { Sufficient phosphorus } \\
\text { (0.280 added to soil) }\end{array}$ & $\begin{array}{l}\text { Sufficient potassium } \\
\text { ( } 0.816 \text { added to soil })\end{array}$ \\
\hline & $\begin{array}{l}\text { Excess nitrogen } \\
\text { added to soil })\end{array}$ & $\begin{array}{l}\text { Excess phosphorus } \\
\text { (3.510 added to soil) }\end{array}$ & $\begin{array}{l}\text { Excess potassium }(1.020 \\
\text { added to soil) }\end{array}$ \\
\hline & $\begin{array}{l}\text { Deficient nitrogen ( } \\
0.603 \text { added to soil) }\end{array}$ & $\begin{array}{l}\text { Deficient phosphorus } \\
\text { (0.378 added to soil) }\end{array}$ & $\begin{array}{l}\text { Deficient potassium } \\
\text { (2.268 added to soil) }\end{array}$ \\
\hline \multirow[t]{2}{*}{ Tuber bulking stage } & $\begin{array}{l}\text { Sufficient nitrogen }(0.804 \\
\text { added to soil) }\end{array}$ & $\begin{array}{l}\text { Sufficient phosphorus } \\
\text { (0.561 added to soil) }\end{array}$ & $\begin{array}{l}\text { Sufficient potassium } \\
(2.652 \text { added to soil) }\end{array}$ \\
\hline & $\begin{array}{l}\text { Excess nitrogen } \\
\text { added to soil })\end{array}$ & $\begin{array}{l}\text { Excess phosphorus } \\
(0.702 \text { added to soil })\end{array}$ & $\begin{array}{l}\text { Excess potassium }(3.570 \\
\text { added to soil) }\end{array}$ \\
\hline
\end{tabular}

\section{Fluorescence}


Chlorophyll fluorescence was measured with Fluorometer (Opti-sciences model) that measure automatically: F0, Fm, F', F0', Fm', Fv/Fm and Fv'/Fm' (table 4 and 5). The application of a saturating pulse to a dark-adapted leaf induces a maximum value of fluorescence by closing reaction centers. The difference between F0 and Fm is the variable fluorescence, Fv. It has been shown theoretically and empirically that $\mathrm{Fv} / \mathrm{Fm}$ constitutes a robust indicator of the maximum quantum yield of PSII chemistry [16, 17]. For unstressed leaves, the value of $\mathrm{Fv} / \mathrm{Fm}$ is highly consistent at $\sim 0.83$ and correlates with the maximum quantum yield of photosynthesis [18]. The presence of any type of stress that causes inactivation damage of PSII [19] or the induction of sustained quenching [20] leads to the lowering of Fv/Fm.

Table 4. Chlorophyll fluorescence parameters

\begin{tabular}{|l|l|}
\hline $\begin{array}{l}\text { Fluorescence } \\
\text { parameters }\end{array}$ & Definition \\
\hline F0 & $\begin{array}{l}\text { Minimal chlorophyll fluorescence intensity measured in the dark-adapted state, when all } \\
\text { PSII reaction centers are open }\end{array}$ \\
\hline Fm & $\begin{array}{l}\text { Maximal chlorophyll fluorescence intensity measured in the dark-adapted state during the } \\
\text { application of a saturating pulse of light }\end{array}$ \\
\hline F'0 & Minimal chlorophyll fluorescence intensity measured in the light-adapted state \\
\hline F'm & $\begin{array}{l}\text { Maximal chlorophyll fluorescence intensity measured in the light-adapted state during the } \\
\text { application of a saturating pulse of light }\end{array}$ \\
\hline Fs & $\begin{array}{l}\text { Chlorophyll fluorescence intensity measured at the steady-state after subjecting the } \\
\text { sample to non-saturating actinic illumination }\end{array}$ \\
\hline Fv & $\begin{array}{l}\text { Variable chlorophyll fluorescence (Fm -F0) measured in the dark-adapted state when } \\
\text { non-photochemical processes are minimum }\end{array}$ \\
\hline F'v & Variable chlorophyll fluorescence (F'm - F'0) measured in the light-adapted state \\
\hline
\end{tabular}

Table 5. List of commonly used abbreviations and equations of chlorophyll fluorescence parameter (Baker, 2008)

\begin{tabular}{|l|l|l|}
\hline Parameter & Formula & Description \\
\hline$F \mathrm{v} / F \mathrm{~m}$ & $(F \mathrm{~m}-F 0) / F \mathrm{~m}$ & $\begin{array}{l}\text { Maximum quantum efficiency of } \\
\text { PSII photochemistry }\end{array}$ \\
\hline$F \mathrm{v}^{\prime} / F \mathrm{~m}^{\prime}$ & $\begin{array}{l}\text { Maximum efficiency of PSII } \\
\text { photochemistry in the light, if all } \\
\text { centers were open. }\end{array}$ \\
\hline
\end{tabular}




\begin{tabular}{|l|l|l|}
\hline$F \mathrm{q}^{\prime} / F \mathrm{~m}^{\prime} \phi \mathrm{PSII}, \Delta F / F \mathrm{~m}^{\prime}$ & $\left(F \mathrm{~m}^{\prime}-F^{\prime}\right) / F \mathrm{~m}^{\prime}$ & $\begin{array}{l}\text { PSII operating efficiency: the } \\
\text { quantum efficiency of PSII } \\
\text { electron transport in the light. }\end{array}$ \\
\hline$F \mathrm{q}^{\prime} / F \mathrm{v}^{\prime} \mathrm{qP}$ & $\left(F \mathrm{~m}^{\prime}-F^{\prime}\right) /\left(F \mathrm{~m}^{\prime}-F 0^{\prime}\right)$ & $\begin{array}{l}\text { Photochemical quenching: relates } \\
\text { PSII maximum efficiency in } \\
\text { operating efficiency. Non-linearly } \\
\text { related to proportion of PSII } \\
\text { centers that are open. See } \mathrm{qL} .\end{array}$ \\
\hline $\mathrm{NPQ}$ & $\left(F \mathrm{~m}-F \mathrm{~m}^{\prime}\right) / F \mathrm{~m}^{\prime}$ & $\begin{array}{l}\text { Non-photochemical quenching: } \\
\text { estimates the rate constant for heat } \\
\text { loss from PSII. }\end{array}$ \\
\hline $\mathrm{qL}$ & $\left(\mathrm{Fq}^{\prime} / \mathrm{fv}^{\prime}\right) /\left(\mathrm{F}^{\prime} / \mathrm{F}^{\prime}\right)$ & $\begin{array}{l}\text { Estimates the fraction of open PSII } \\
\text { centres. }\end{array}$ \\
\hline
\end{tabular}

\section{Carbohydrates accumulation and distribution in leaves, stems and tubers}

\section{Determination of total sugars content}

Three replicates of leaves, stems and tubers samples were suspended in test tubes with $3 \mathrm{ml}$ of $80 \%$ ethanol, the extract was then filtered and the filtrate was dissolved in $20 \mathrm{ml}$ of distilled water. Total soluble sugars, reducing sugars and sucrose were determined by the phenol-sulfuric acid method [22] using glucose as standard.

\section{Number and weight of tubers per plant}

The number of tubers was determined by a simple counting of tubers produced per plant. The weight of tubers was taken directly after harvest.

\section{RESULTS}

\section{Effects of different NPK levels on chlorophyll fluorescence parameters}

Minimal fluorescence F0 (Minimal chlorophyll fluorescence) is low in case of a plant with no stress and increases in case of stress and conversely for Fm (Maximal chlorophyll fluorescence). Between those two fluorescence limits (F0 and Fm), we can calculate the quantum efficiency component $(\mathrm{Fv} / \mathrm{Fm})$ which is always less than 1 . This quantum efficiency decreases when the level of inhibitors increases. Average effect of cultivars on chlorophyll fluorescence parameter was significant at the level of 1\%, except evapotranspiration ETR (table 6, Figure 1). Spunta showed the highest value of F0 with 719.155, Daifla (695.251). Regarding the Photosynthetic 
Active Radiation PAR, Daifla showed the highest value with 1063.888, which was significantly different compared to Spunta with 859,244.

Both tested cultivars showed an Fv/Fm low than 0.83 indicate a stressed state for all plants under all NPK rates. This physiological stress could be explained by high temperature and long photoperiod growing conditions. Daifla showed an Fv/Fm more elevated compared to Spunta with 0.774 and 0.608 respectively.

For $\mathrm{Fq}^{\prime} / \mathrm{Fm}^{\prime}$ : is the PSII operating efficiency: the quantum efficiency of PSII electron transport in the light, Spunta also showed the lowest value with 0.611 , which was significantly different compared to Daifla with 0.657 .

NPQ is an estimation of the rate constant for heat loss from PSII (Photosystem II) which is admitted to be between 0.5 and 3.5. Our data showed that Daifla presented the lowest value of this parameter with 1.966 which was different compared to Spunta with 2.853 .

$\mathrm{qL}$ is an estimation of the fraction of open PSII. For this parameter, Daifla showed the lowest value with 0.885 , compared to Spunta with a qL about 1.049 .

Table 6. Impact of cultivar on chlorophyll fluorescence parameters

\begin{tabular}{|c|c|c|c|}
\hline & F0 & $\mathrm{Fm}$ & $\mathrm{FV}$ \\
\hline Spunta & $719.155^{\mathrm{a}} \pm 21.605$ & $2700.088^{\mathrm{a}} \pm 64.953$ & $1494.355^{b} \pm 55.160$ \\
\hline \multirow[t]{2}{*}{ Daifla } & $695.251^{\mathrm{b}} \pm 14.370$ & $2213.511^{b} \pm 20.847$ & $2004.837^{\mathrm{a}} \pm 17.714$ \\
\hline & $\mathrm{F}^{\prime}$ & Fm' & $\mathrm{Fv}^{\prime}$ \\
\hline Spunta & $207.718^{b} \pm 8.345$ & $768.2740^{b} \pm 40.77$ & $505.881^{b} \pm 33.824$ \\
\hline \multirow[t]{2}{*}{ Daifla } & $327.518^{a} \pm 13.727$ & $1074.192^{\mathrm{a}} \pm 33.098$ & $635.770^{\mathrm{a}} \pm 28.601$ \\
\hline & F0' & ETR & PAR \\
\hline Spunta & $274.362^{b} \pm 14.374$ & $98.509^{a} \pm 8.025$ & $859.244^{b} \pm 41.742$ \\
\hline Daifla & $441.637^{\mathrm{a}} \pm 16.696$ & $111.699^{\mathrm{a}} \pm 8,923$ & $1063.888^{\mathrm{a}} \pm 34.601$ \\
\hline
\end{tabular}

Means followed by the same letters are not significantly different $(\mathrm{P}<0.01)$ according to Duncan's test

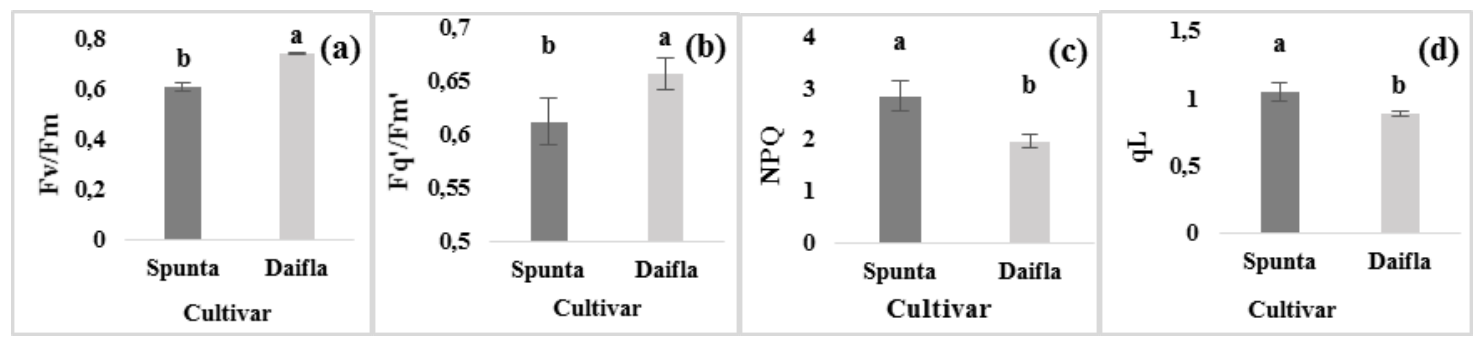


Fig 1. Average effect of cultivar on relevant parameters of chlorophyll fluorescence. (a) Average effect of cultivar on Fv/Fm. (b) Average effect of cultivar on Fq'/Fm'. (c) Average effect of cultivar on NPQ. (d) Average effect of cultivar on qL.

There was a significant interaction cultivar*fertilization $(\mathrm{P} \leq 0.01)$ for chlorophyll fluorescence parameters (table 7, Figure 2).

Interaction cultivar*fertilization influenced significantly chlorophyll fluorescence parameters including F0, Fm, Fv (Variable chlorophyll fluorescence (Fm - F0)), F' (Chlorophyll fluorescence intensity measured at the steady-state), Fm' (Maximal chlorophyll fluorescence intensity measured in the light-adapted state), Fv' (Variable chlorophyll fluorescence (F'm F'0)), F0' (Minimal chlorophyll fluorescence intensity measured in the light-adapted state), ETR, PAR, Fv/Fm, Fv'/Fm' (Maximum efficiency of PSII photochemistry in the light), Fq'/Fm', NPQ and $\mathrm{qL}$ (see tables 4 and 5 for abbreviations meaning).

Regarding Spunta cultivar, the lowest value of F0 was that of excess NPK doses with 663.667. Maximum Fm, was that of deficiency NPK doses with 2474.444 , followed by optimum rates with 2335.800. It showed also the highest photosynthesis yield under deficiency regime with 0.691. Excess regime gave plants with an Fv/Fm about 0.484, indicates a very stressed state of plants concerning photosynthesis.

Daifla, showed a low F0, under deficiency and optimum regimes. Highest level of Fm was detected under optimum and deficiency NPK rates with respectively 2749 and 2719. This cultivar showed similar Fv/Fm for all fertilization conditions.

ETR values were very similar under deficiency regimes for both cultivars. While under excess regime of fertilizers, the difference was more important with high value recorded with Daifla.

Concerning the PAR, the difference between tested cultivars was also more pronounced under excess NPK levels, which was shown for Daifla cultivar.

Table 7. Impact of cultivar and fertilization on chlorophyll fluorescence parameters

\begin{tabular}{|c|c|c|c|c|c|c|}
\hline & \multicolumn{2}{|l|}{ Fo } & \multicolumn{2}{|l|}{$\mathbf{F m}$} & \multicolumn{2}{|l|}{$\mathbf{F v}$} \\
\hline & Spunta & Daifla & Spunta & Daifla & Spunta & Daifla \\
\hline Deficient & $734.489 \pm 29.881$ & $685.556 \pm 21.265$ & $2474.444 \pm 50.482$ & $2719.733 \pm 40.309$ & $1739.956 \pm 61.104$ & $2034.178 \pm 28.348$ \\
\hline Sufficient & $759.311 \pm 30.218$ & $686.867 \pm 29.511$ & $2335.800 \pm 99.162$ & $2749.111 \pm 35.818$ & $1576.489 \pm 103.298$ & $2062.244 \pm 23.118$ \\
\hline \multirow[t]{3}{*}{ Excess } & $663.667 \pm 33.773$ & $713.333 \pm 33.773$ & $1830.289 \pm 177.037$ & $2631.422 \pm 45.639$ & $1166.622 \pm 129.875$ & $1918.089 \pm 45.573$ \\
\hline & \multicolumn{2}{|l|}{$\mathbf{F}^{\prime}$} & \multicolumn{2}{|l|}{ Fm' } & \multicolumn{2}{|l|}{$\mathbf{F v} \mathbf{v}^{\prime}$} \\
\hline & Spunta & Daifla & Spunta & Daifla & Spunta & Daifla \\
\hline Deficient & $227.822 \pm 10.178$ & $318.511 \pm 22.475$ & $854.378 \pm 69.633$ & $810.387 \pm 41.924$ & $558.467 \pm 61.597$ & $411.822 \pm 28.715$ \\
\hline Sufficient & $202.956 \pm 9.125$ & $296.711 \pm 25.889$ & $833.844 \pm 85.322$ & $1116.711 \pm 56.916$ & $554.756 \pm 70.897$ & $719.778 \pm 50.722$ \\
\hline \multirow[t]{3}{*}{ Excess } & $192.378 \pm 25.084$ & $367.333 \pm 31.744$ & $616.600 \pm 82.365$ & $1295.489 \pm 67.313$ & $404.422 \pm 66.688$ & $77.711 \pm 64.121$ \\
\hline & \multicolumn{2}{|l|}{ F0' } & \multicolumn{2}{|l|}{ ETR } & \multicolumn{2}{|l|}{ PAR } \\
\hline & Spunta & Daifla & Spunta & Daifla & Spunta & Daifla \\
\hline Deficient & $290.889 \pm 26.755$ & $404.533 \pm 24.197$ & $102.304 \pm 16.970$ & $102.329 \pm 10.766$ & $947.822 \pm 66.548$ & $790.378 \pm 47.364$ \\
\hline
\end{tabular}




\begin{tabular}{lllllll} 
Sufficient & $320.022 \pm 25.257$ & $403.511 \pm 34.597$ & $127.820 \pm 15.382$ & $109.467 \pm 22.572$ & $1037.778 \pm 77.860$ & $1116.711 \pm 56.916$ \\
Excess & $212.178 \pm 30.641$ & $512.867 \pm 36.168$ & $65.404 \pm 13.758$ & $123.302 \pm 17.987$ & $592.133 \pm 84.153$ & $1284.578 \pm 71.332$ \\
\hline
\end{tabular}

$\mathrm{Fv}^{\prime} / \mathrm{Fm}^{\prime}$ is the maximum efficiency of PSII photochemistry in the light, if all centers were open, this parameter was found to be more important under deficient npk levels for both studied cultivars.

The same behavior was found for $\mathrm{Fq} / \mathrm{Fm}$ ' with highest levels under deficient followed by optimum NPK rates for both tested cultivars, with a very low value under excess NPK levels for Spunta cultivar.

Regarding the photo inhibition NPQ, studied cultivars behaved differently depending on NPK level. Spunta showed the highest value under sufficient NPK rates indicates a situation of light stress in this condition. Daifla presented the highest NPQ values under deficient and excess NPK regimes.

Concerning the fraction of open PSII qL, Spunta gave the highest values under deficient and excess regimes, while Daifla showed a similar behavior under all NPK levels.

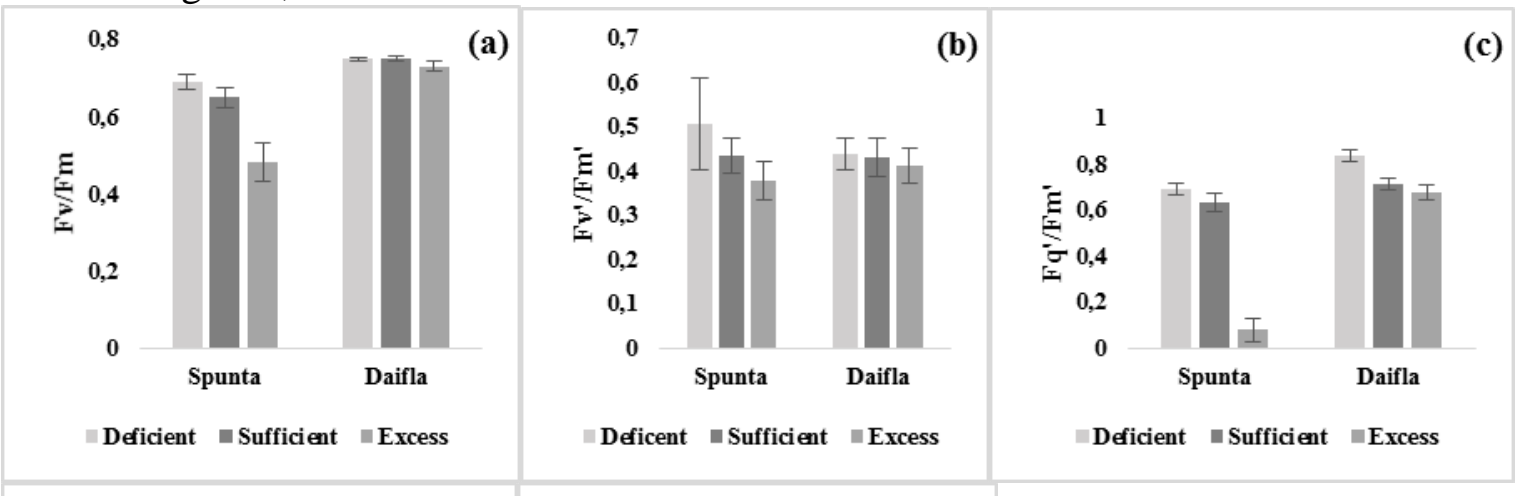

(d)

(e)
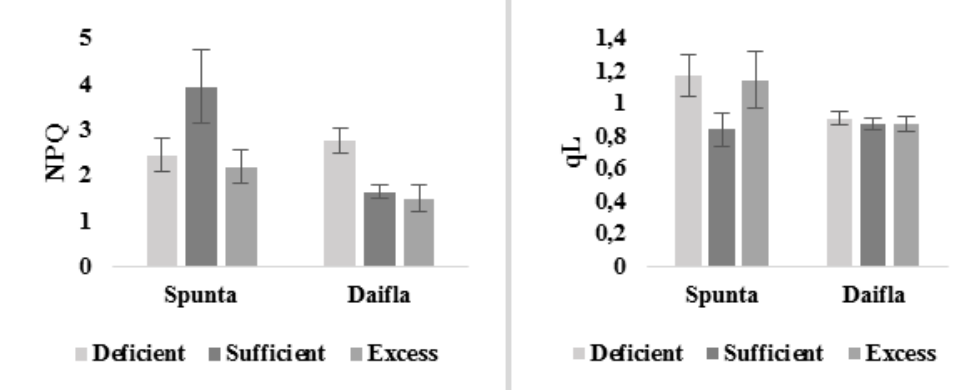

Fig 2. Average effects of cultivar and NPK levels on chlorophyll fluorescence parameters. (a) NPK levels*cultivar on Fv/Fm. (a) NPK levels*cultivar for Fv'/Fm'. (c) NPK levels*cultivar for Fq'/Fm'. (d) NPK levels*cultivar for NPQ. (e) NPK levels*cultivar for qL. 
Our data showed that Spunta cultivar was no more photosynthetic during the tuber maturation stage (78 DAP) under excess NPK levels which is illustrated in figure 3 including F0, Fm, $\mathrm{Fv} / \mathrm{Fm}, \mathrm{ETR}$ and PAR.

There was a shift between the behavior of Spunta cultivar under deficient and sufficient NPK rates for photosynthesis parameters, except a surprising decrease of Fm, Fv/Fm and ETR during 64 DAP under sufficient NPK rates.

Interaction NPK rates*date of the measure was also significant for the major of fluorescence parameters for Daifla cultivar, except Fm. Evolution behavior of this cultivar, concerning F0 and $\mathrm{Fv} / \mathrm{Fm}$ indicates that plants were more unstressed during 78 DAP in all NPK regimes.

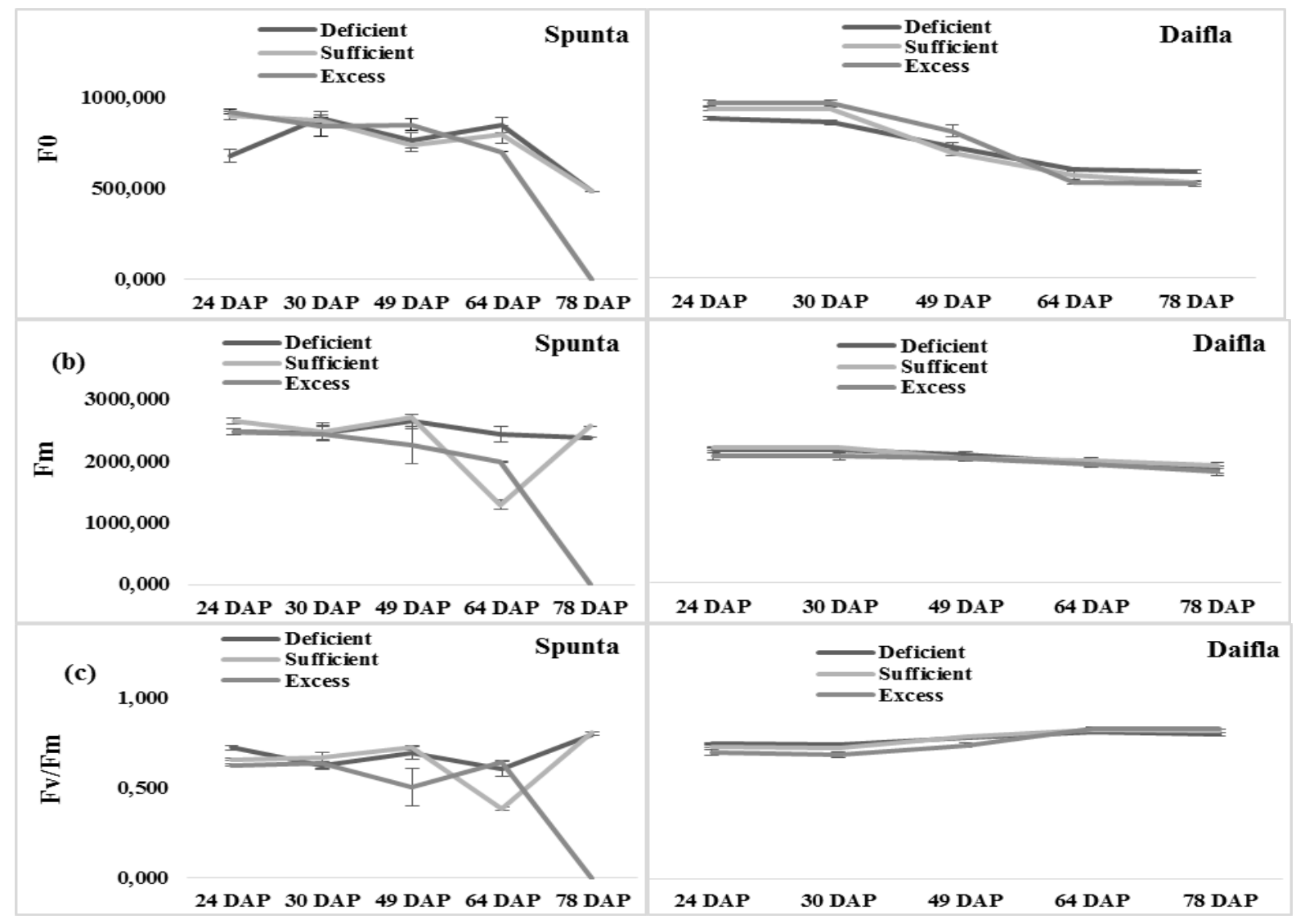




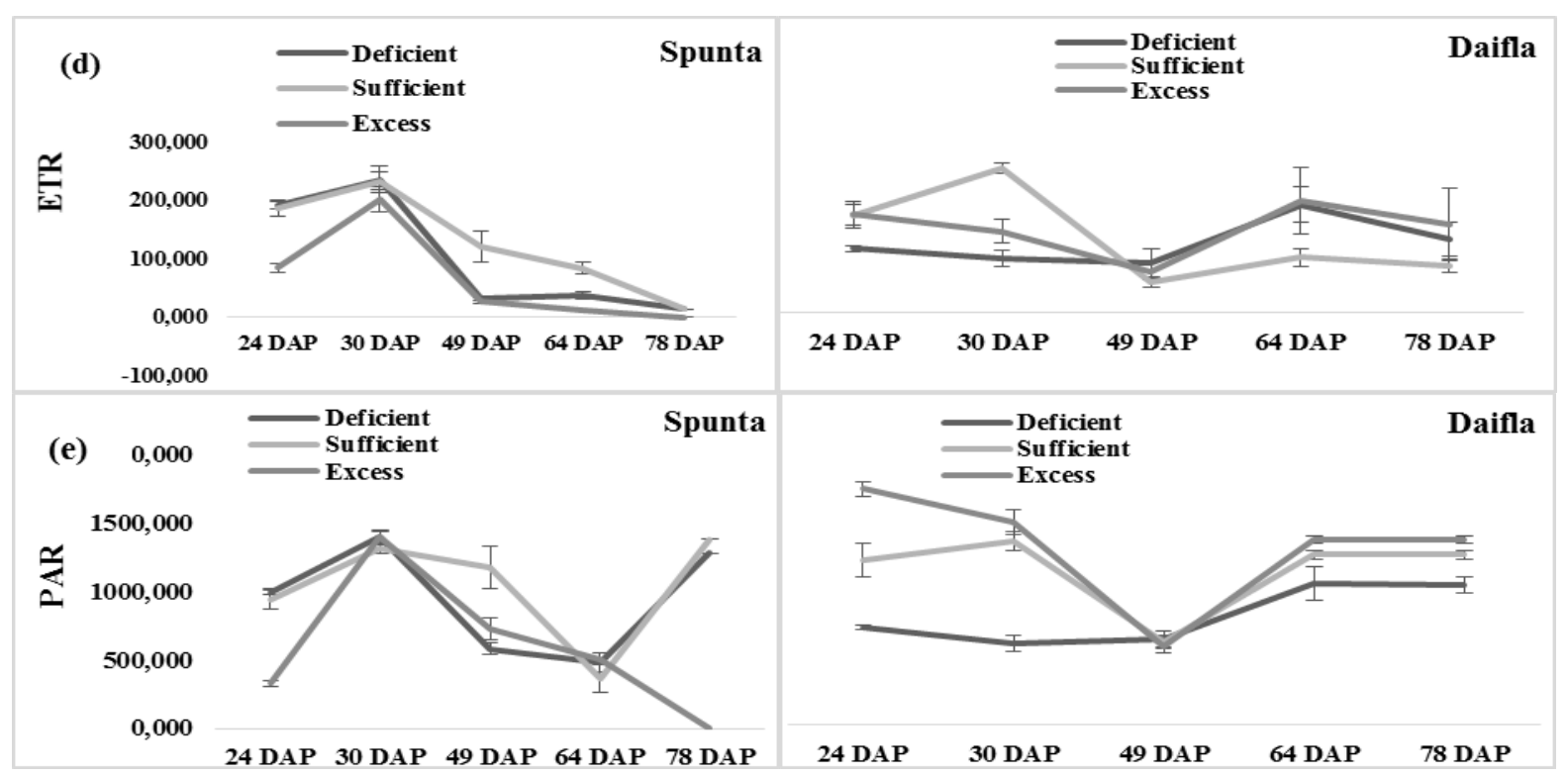

Fig 3. Effects fertilization and harvest date on chlorophyll fluorescence parameters. (a) Interaction fertilization*date of measure for F0. (b) Interaction fertilization*date of measure for Fm. (c) Interaction fertilization*date of measure for Fv/Fm. (d) Interaction fertilization*date of measure for ETR. (e) Interaction fertilization*date of measure for PAR.

\section{Effects of different NPK levels on soluble sugars content in source, phloem and sink organs}

The growth of potato tubers depends on assimilates supplied by the source. Source capacity affects yield directly. Our study used the soluble sugars average content in leaves, stems and tubers to assess assimilates distribution in potato in response to different NPK rates as affected by elevated temperature and long photoperiod conditions. Table 8 showed no significant differences between tested cultivars concerning soluble sugars amounts in leaves. Spunta, a midearly cultivar, accumulated more sugars in phloem and tubers compared to Daifla as a mid-late cultivar.

Table 8. Average effect of cultivar on soluble sugars accumulation in different organs

\begin{tabular}{llll}
\hline & Mg/g FW & & \\
& Soluble sugars & & \\
\hline & Source & Phloem & Sink \\
Spunta & $0.998^{\mathrm{a}} \pm 0.041$ & $\mathbf{1 . 2 1 8}^{\mathrm{a}} \pm \mathbf{0 . 0 7 4}$ & $\mathbf{1 . 8 6 7}^{\mathrm{a}} \pm \mathbf{0 . 0 8 2}$ \\
Daifla & $0.975^{\mathrm{a}} \pm 0.050$ & $\mathbf{1 . 0 5 4}^{\mathrm{b}} \pm \mathbf{0 . 0 4 8}$ & $\mathbf{1 . 1 3 8}^{\mathbf{b}} \pm \mathbf{0 . 0 6 3}$ \\
\hline
\end{tabular}


There was a significant interaction NPK rates-by-cultivar for soluble sugars content in the phloem (Figure 4). Both cultivars accumulated more sugars in phloem under deficient NPK levels. A shift between sufficient and excess regimes was detected in this trait for Spunta cultivar, while lowest amount was that of excess NPK rates for Daifla cultivar.

Concerning soluble sugars accumulation in sink organs, cultivars behaved differently depending on NPK rates. Spunta accumulated the highest amount of sugars in tuber under sufficient regimes with a shift between deficient and excess treatments. Daifla showed similar amounts of sugar under deficient and optimum regimes and gave the lowest sugars content in excess NPK levels.

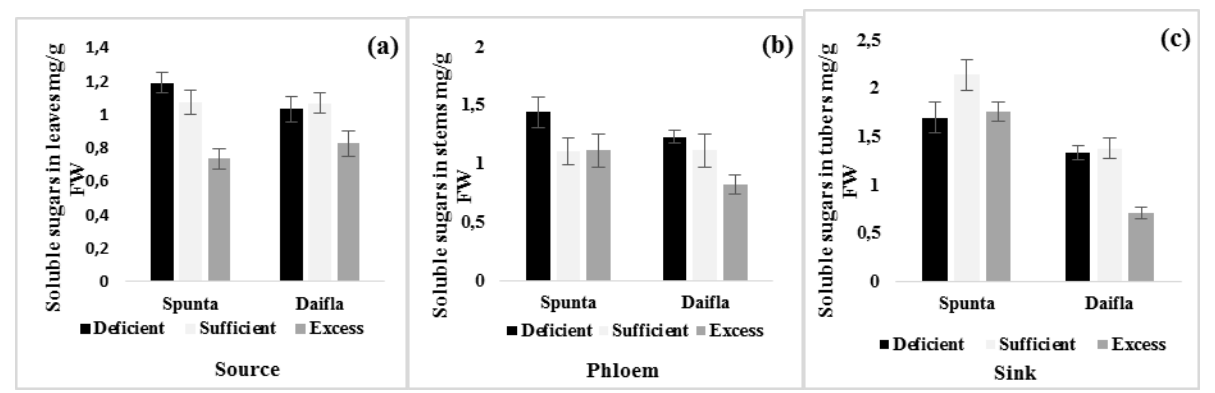

Fig 4. Average effects of cultivar and NPK levels on soluble sugars content in different organs (mg/g FW). (a) Interaction cultivar*NPK levels for soluble sugars amount in leaves. (b) Interaction cultivar*NPK levels for soluble sugars amount in stems. (c) Interaction cultivar*NPK levels for soluble sugars amount in tubers.

Figure 5 showed a significant interaction NPK rates*date of measure for soluble sugars content in leaves for both studied cultivars. Regarding Spunta, a shift between sufficient and excess NPK levels was found at 30 and 49 DAP. From 64 DAP, deficiency NPK regime gave the highest sugars amounts in levaes, while excess rates produced the lowest sugars content in source organ at all different date of harvest.

Daifla showed a different behavior concerning this trait with highest soluble sugars content in leaves under sufficient and excess NPK rates at 30 DAP. Surprisingly at 49 DAP (tuber bulking stage) those two regimes gave the lowest sugars accumulation in leaves, with an important increase of sugars under the deficient regime. At 64 a 78 DAP, a remarkable shift was detected between excess and sufficient NPK levels for this trait.

No interaction NPK rates*date of the measure was found for Daifla cultivar for soluble sugars in phloem and tubers organs, while for Spunta, a significant interaction was found for sugars accumulation in stems. Deficient NPK rates produced more sugars at 49 and 64 DAP, excess regime gave the highest sugars amounts at 78 DAP (tuber maturation stage).

For sugars accumulation in tubers, at 49 and 78 DAP, Spunta accumulated more sugars under sufficient NPK rates, while at 64 DAP (tuber bulking) the highest sugars content in sink organs was found under the excess regime. 


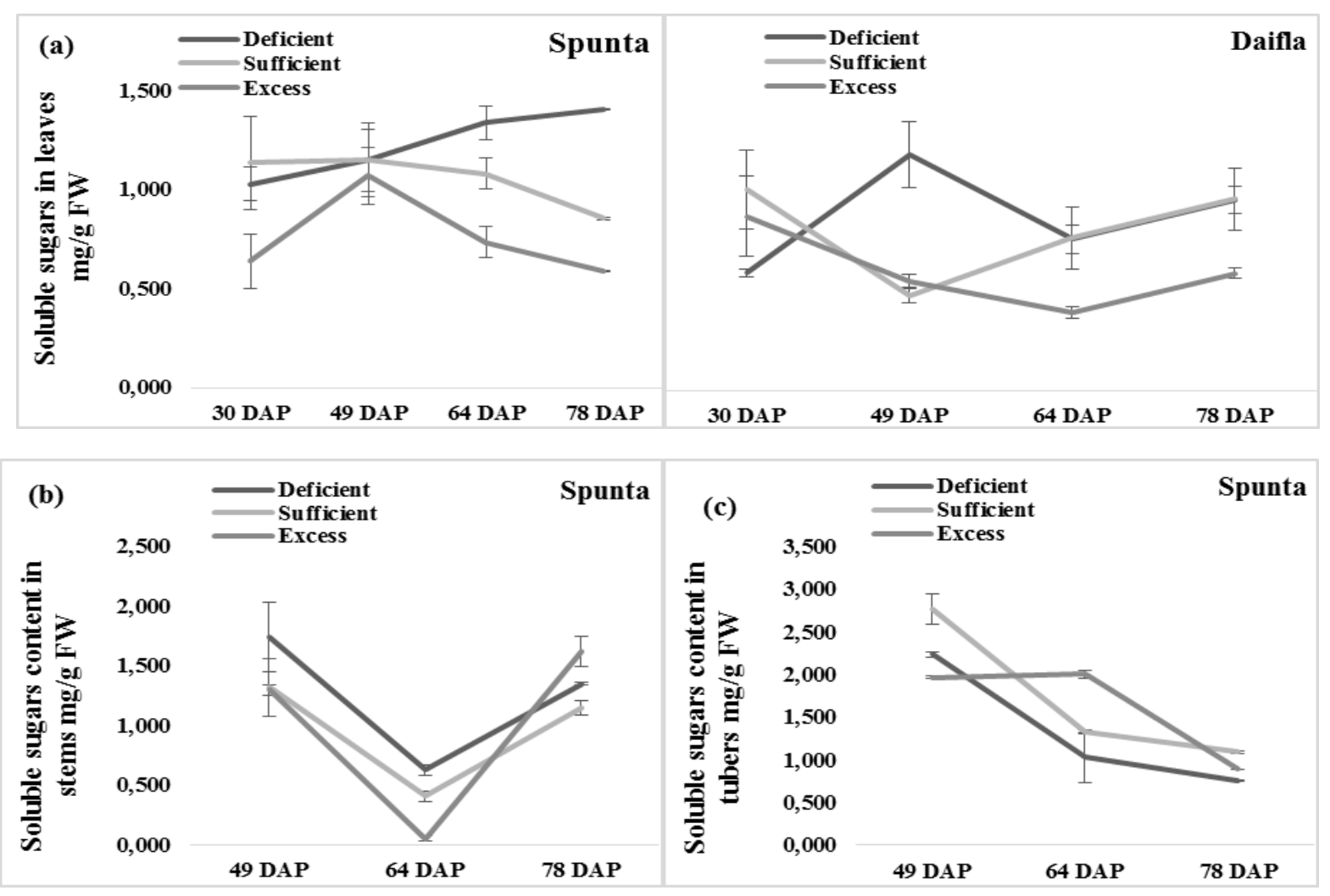

Fig 5. Average effects of cultivar and date of measure on soluble sugars content in different organs (mg/g FW). (a) Interaction cultivar*date of measure for soluble sugars amount in leaves. (b) Interaction cultivar*date of measure for soluble sugars amount in stems. (c) Interaction cultivar*date of measure for soluble sugars amount in tubers.

\section{Effects of NPK levels on tuber yield}

The measure of final average tubers yield (table 9 ) showed a highly significant impact of cultivar on this trait $(\mathrm{P}<0.01)$. The highest weight of tubers per plant was produced by Spunta cultivar with $110.522 \mathrm{~g}$ per plant. Daifla produced tubers with very low weight about $4.822 \mathrm{~g}$ with also few number about 3.074 tubers/plant.

There was a significant interaction $(\mathrm{P}<0.01)$ cultivar*fertilization for tuber yield par plant (Figure 6). Spunta produced the highest weight of tuber per plant under sufficient and deficient rates of NPK, Daifla produced a very low tuber weight, even the highest tuber weight was recorded under excess NPK levels;

Table 9. Average effects of cultivar on tuber yield

\begin{tabular}{lll}
\hline & $\begin{array}{l}\text { Weight of tubers per plant } \\
(\mathrm{g})\end{array}$ & $\begin{array}{l}\text { Number of tubers per } \\
\text { plant }\end{array}$ \\
\hline Spunta & $\mathbf{1 1 0 . 5 2 2}^{\mathrm{a}} \pm \mathbf{3 . 0 0}$ & $\mathbf{6 . 5 5 5}^{\mathrm{a}} \pm \mathbf{0 . 1 9 9}$ \\
Daifla & $\mathbf{4 . 8 2 2}^{\mathbf{b}} \pm \mathbf{0 . 1 8 7}$ & $\mathbf{3 . 0 7 4}^{\mathrm{b}} \pm \mathbf{0 . 2 2 0}$ \\
\hline
\end{tabular}


Means followed by the same letters are not significantly different $(\mathrm{P}<0.01)$ according to Duncan's test.

Figure 6 showed the number of tubers/plant. Spunta produced more tuber under deficiency NPK regime. Daifla gave more number of tuber under excess NPK doses.

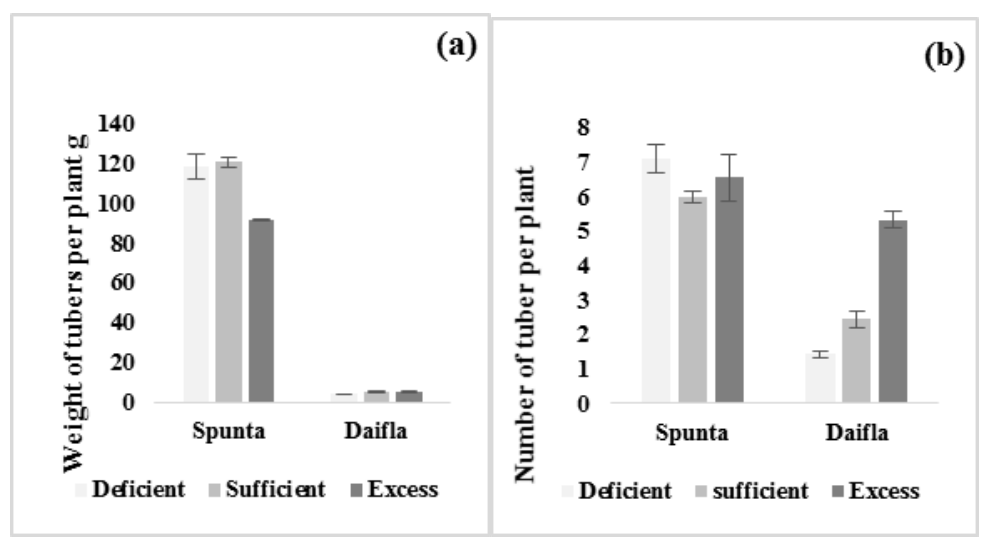

Fig 6. Average effects of cultivar and NPK levels on tuber yield per plant. (a) Interaction cultivar*NPK levels for weight of tubers/ plant (g). (b) Interaction cultivar*NPK levels for the number of tubers/ plant.

Interaction, NPK levels*date of the measure was not significant for Daifla cultivar. Eve nit produced highest weight and number of tubers under excess regimes in all date of harvest, including 49, 64 and 78 DAP. Regarding Spunta cultivar, there was a shift in potato tuber weight under sufficient and deficient NPK rates, low tuber weight was recorded under excess NPK levels in all dates of measure. For this trait deficient regime gave highest number of tubers, followed by excess; those data suggested that for Spunta, mid-early cultivar, sufficient NPK rates gave the plant with highest weight of tubers but low size (Figure 7).

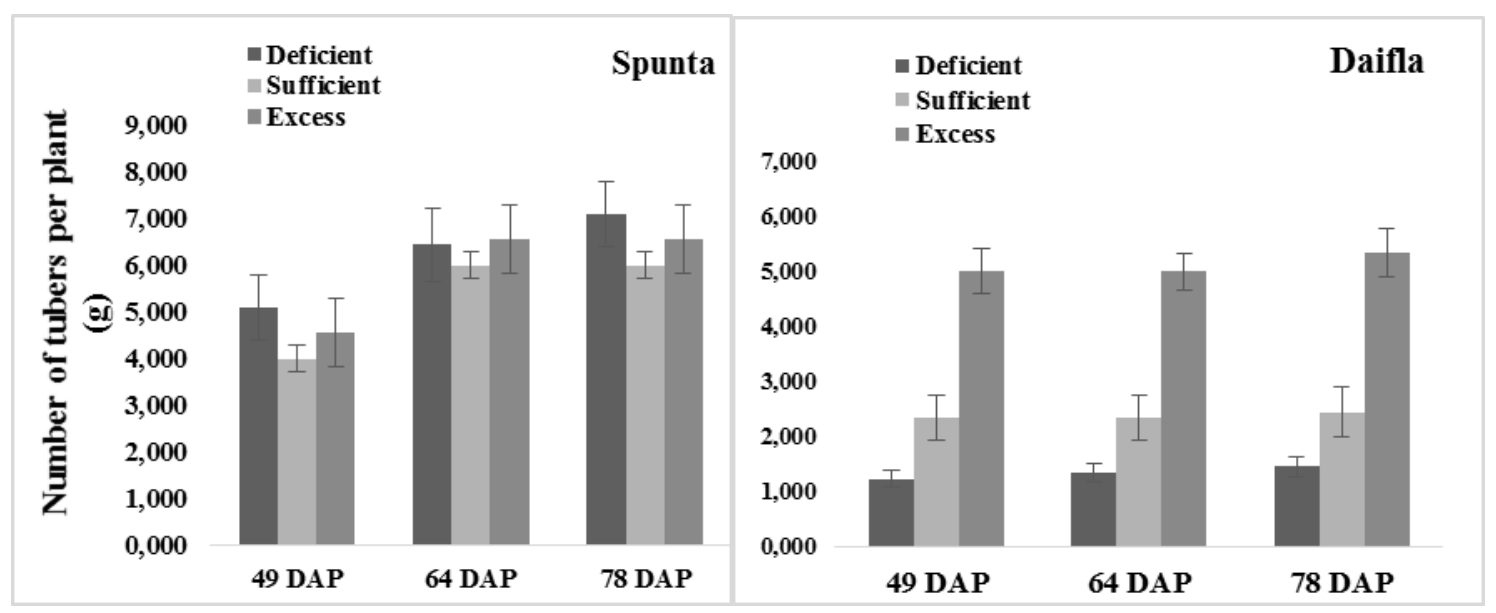




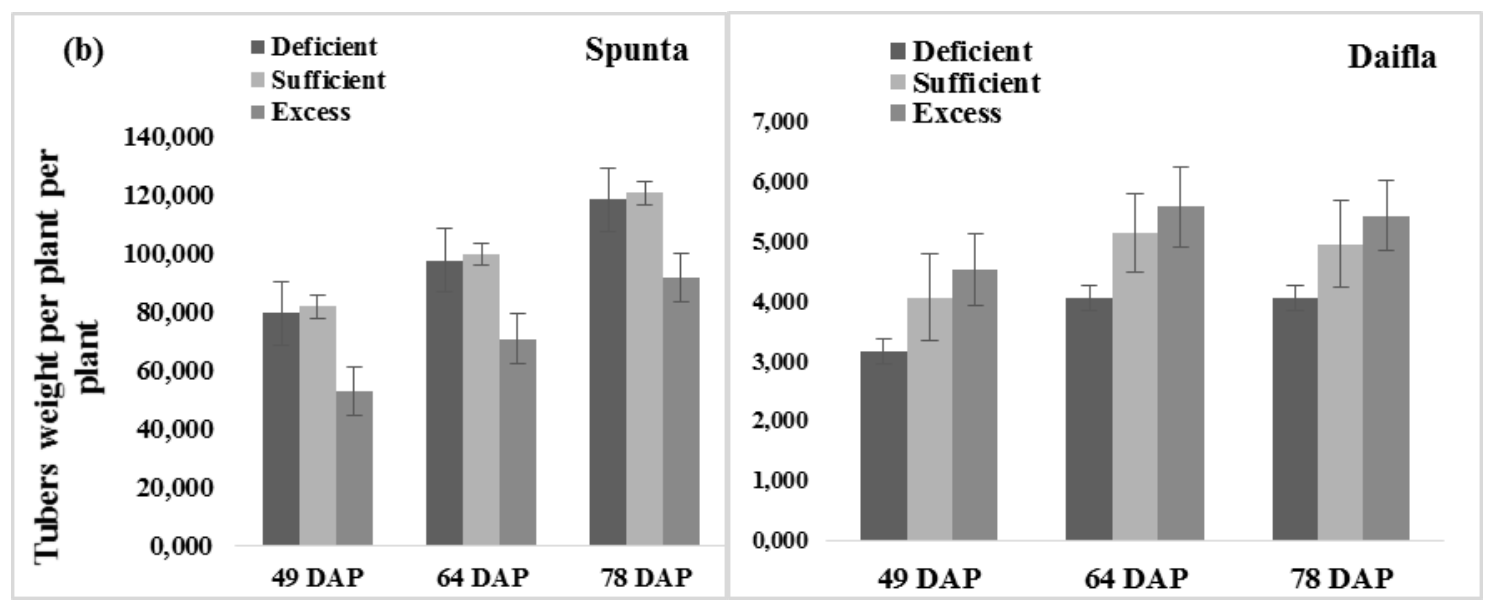

Fig 7. Average effect of cultivar and date of measure on tuber yield per plant. (a) Interaction cultivar*date of measure for the number of tubers per plant (g). (b) Interaction cultivar*date of measure for tuber weight per plant.

Our study used relevant parameters of chlorophyll fluorescence, sugars content in leaves, stems and tubers, as well as production parameters, stems to assess accumulation and distribution of assimilates in potato plant. Table 10 showed that during the tuber bulking stage (49 DAP), the tuber weight per plant is correlated to F0, Fm', Fv' and soluble sugars content in both stems and tubers. While it was negatively correlated to $\mathrm{F}^{\prime}, \mathrm{Fv} / \mathrm{Fm}$ as well as Fv'/Fm'.

At this stage, the tuber number per plant was also correlated to F0, Fv', soluble sugars amount in source and the tuber weight. A negative correlation was found between tuber number and F0'.

During the tuber filling stage (64 DAP), tuber yield per plant including weight and number of tubers was positively correlated to F0, Fv'/Fm', NPQ and qL and negatively correlated to fm, Fv, Fm', Fv', F0', ETR and PAR and soluble sugars in stems. During this stage of tuberization tuber number was also correlated to tuber weight.

At 78 DAP (tuber maturity), tuber weight was positively correlated to F0 and NPQ. It was negatively correlated to the most of chlorophyll parameters as well as sugars content in tubers.

During this stage, tuber number was negatively correlated to the major of chlorophyll parameters, soluble sugars accumulation in leaves and tubers. While it was positively correlated to sugars amounts in stems and also to the tuber weight.

Our data suggest that plant with high photosynthesis performance produced low tuber yield per plant under all NPK levels. This could be the effect of high temperature and long photoperiod growth conditions that promote vegetative growth and could reduce the amounts of assimilates transported to the sink organ. 
Table 10. Pearson correlation coefficients among tuber yield and some relevant parameters during the tuber bulking stage (49 DAP), filling stage (64 DAP) and tuber maturation (78 DAP)

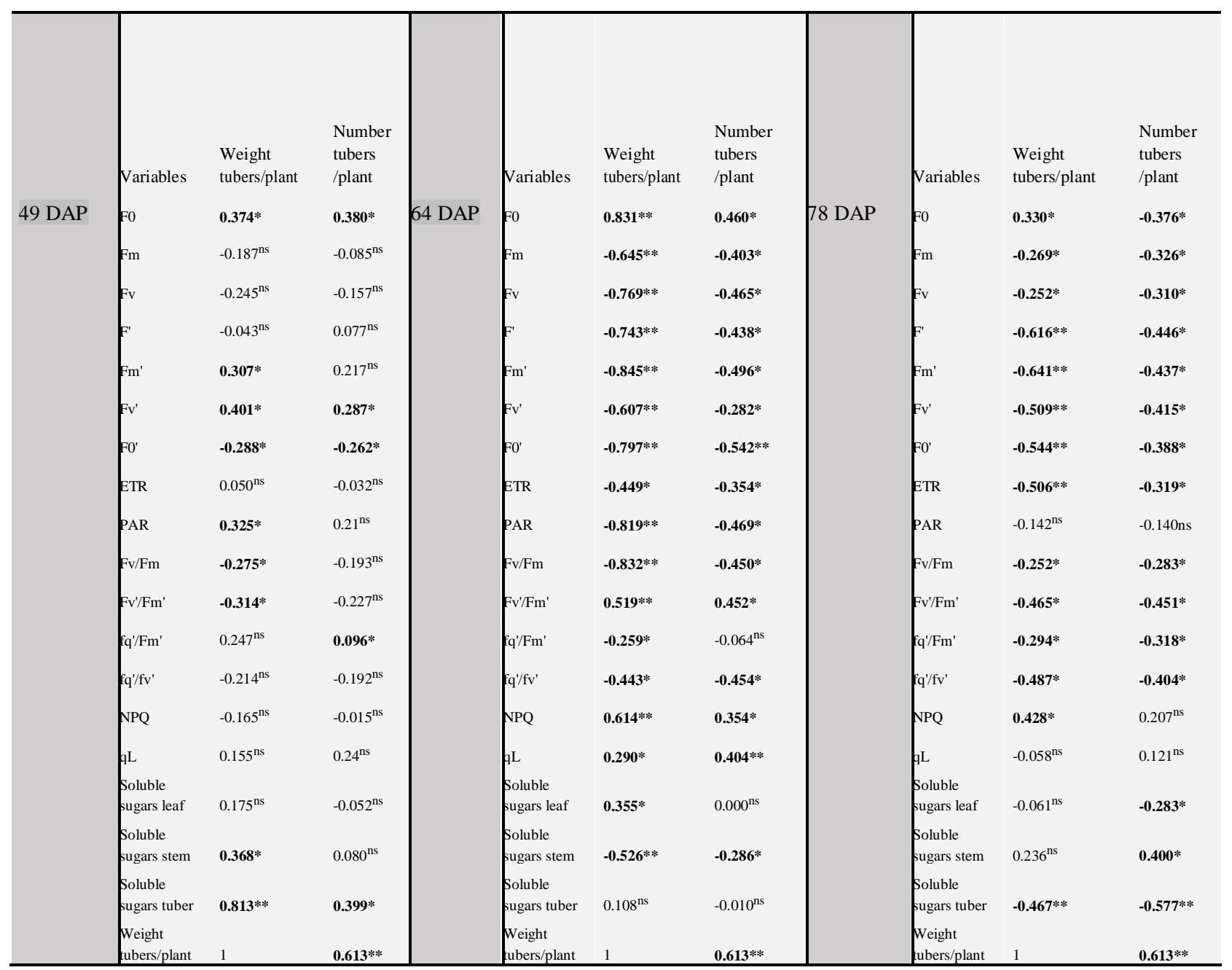

* significantly different at $\mathrm{p} \leq 0.05$;** significantly different at $\mathrm{p} \leq 0.01$; ns: not significant

\section{DISCUSSION}

Application of fertilizers including nitrogen, potassium and phosphorus is as important as environmental factors and genotypes for enhancing crop yields [23]. However, excessive fertilizer could not give an increase in yield [24, 25].

Potato plant needs a high level of nitrogen for a fast cycle and high growth rate [26]. Those finding are in agreement with our data showed that Spunta, as a mid-early cultivar, performed better for this trait under deficiency NPK rates, and showed a very low Fv/Fm under excess fertilization (about 0.4), and recorded a complete loss of leaves photosynthetic activity under excess fertilization during the tuber maturity stage (Figure 8). Spunta cultivar recorded also under excess NPK rates, the lowest sugars content in source organ at all different date of harvest. 
Excess NPK regimes gave the highest sugars amounts in stems at 78 DAP (tuber maturation stage), during this stage, Spunta accumulated more sugars in tubers under sufficient NPK rates. Those observations, are in disagreement with those of Robredo et al. [27] and Jin et al. [28] found that nitrogen stress may limit photosynthesis and influence partition of photoassimilates from leaves to tubers. For this parameter, Daifla, as mid-late cultivar, recorded similar Fv/Fm for all fertilization conditions.

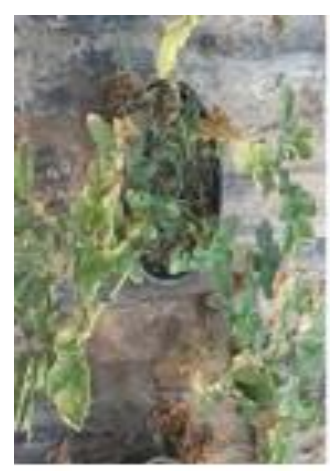

Deficient

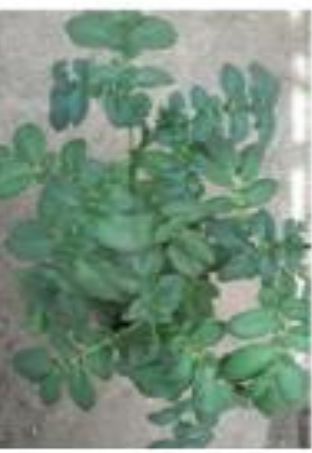

Deficient

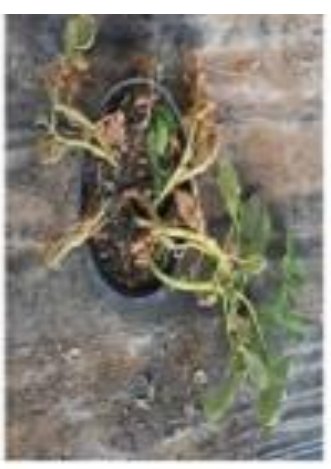

Sufficient

Spunta

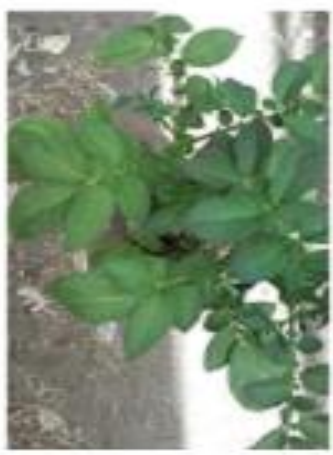

Sufficient

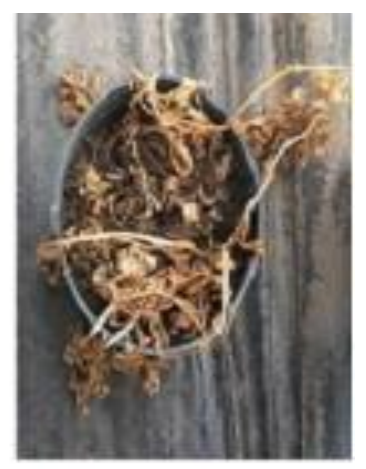

Excess

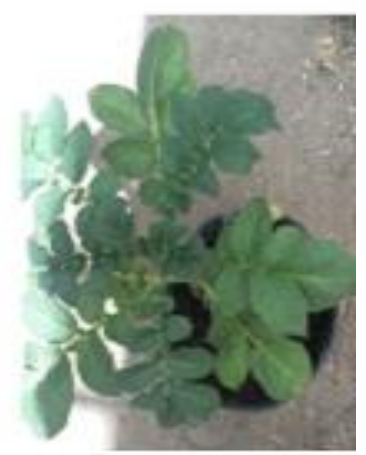

Excess

Daifla

Fig 8. Spunta and Diafla under different NPK levels during tuber maturation stage (78 DAP)

At 49 DAP (tuber bulking stage), Daifla gave the lowest sugars accumulation in leaves under sufficient and excess regimes. At 64 and 78 DAP, a remarkable shift was detected between excess and sufficient NPK levels for this trait. No interaction NPK rates*date of the measure was found for Daifla cultivar for soluble sugars in phloem and tubers organs. 
In case of nitrogen deficiency, a reduced vegetation cover with an early leaf senescence which could result in a reducing tuber yield. Excess of nitrogen supply can cause a delay in the time of tuber growth and development and promote vegetative growth which can also result in reducing yields [29, 30]. It was reported that a higher $\mathrm{N}$ availability has a positive effect on vegetative growth and light interception, which leads to high tuber yield [26].

Nitrogen is knowing to be the most important nutrient for the potato plant, and then potato tuber yield is highly affected by its availability [31, 32]. Usually, $\mathrm{N}$ increases yield [33].

Spunta produced highest weight and number of tuber per plant under sufficient rates of NPK, followed by deficiency regime. Daifla produced tubers with highest weight and number under excess NPK levels. Those finding are in agreement with those reported earlier by Krauss [34] demonstrated that an excess in nitrogen gave to the leaf did not promote tuberization. Koda and Okazawa [35], suggested also that the ratio of carbohydrate to nitrogen is important. High levels of photoassimilates are in favor of tuber development, whereas excess of nitrogen can promote shoot and root growth that would utilize much of the available carbohydrate and reduce the amount available for tuber formation.

With both of deficient and excess of nitrogen regimes, photosynthesis, leaf area and tuber yield are lower than under optimum nitrogen condition. This result could be explained by the fact that with deficient and excess nitrogen supply, source and sink activities are lower than under optimal nitrogen fertilization, which generally results in lower tuber yield (number and weight of tubers). In this same context, earlier report demonstrated that potato plants grown under low $\mathrm{N}$ fertilization rates have lost their photosynthetic ability in mature leaves towards the end of their development cycle [36].

\section{CONCLUSION}

NPK doses including deficiency and excess severely compromise physiological efficiency of potato plants. Tuberization process in potato (Solanum tuberosum) is thought to be controlled by the interaction between genotype and environmental factors. Impact of photoperiod, temperature and mineral nutrition depending on cultivar which can cause variations in potato response to those environmental conditions. This study makes out differences in growth, metabolites and yield between mid-early and mid-late potato cultivars subjected to different rates of nitrogen, phosphorus and potassium fertilizers and growing under high temperature and long photoperiod conditions. During subsequent growth stages. Mid-early potato cultivar showed a complete loss of photosynthetic activity under excess NPK levels during the tuber maturation stage. The midlate cultivar kept a good photosynthetic performance until the tuber 78 DAP in all NPK levels but with very low tuber yield per plant. This could be explained by the effect of high temperature and long photoperiod growth conditions which results in a decrease in tuber yield and an increase in photosynthesis in source leaves.

\section{REFERENCES}

[1] Pereira A, Villa Nova N .2008. Potato maximum yield as affected by crop parameters and climatic factors in Brazil, HortScience, vol. 43 no. 5, 1611-1614 
[2] Beukema HP, van der Zaag DE .1990. Introduction to potato production, Pudoc Wageningen, 53-56

[3] Mikkelsen R .2006. Best management practices of profitable fertilization on potatoes, Better Crops, vol. 90, nr. 2

[4] Oliveira CAS. 2000. Potato crop growth as affected by nitrogen and plant density. Pesq Agropec Bras 35:939-50

[5] Vos J, Biemond H, 1992, Effects of nitrogen on the development and growth of the potato plant. 1. Leaf appearance, expansion growth, life spans of leaves and stem branching. Annals of Botany. 70 (1):27-35

[6] Goffart JP, Olivier M, Frankinet M .2008. Potato crop nitrogen status assessment to improve $\mathrm{N}$ fertilization management and efficiency : past-present-future. Potato Res 51:355-383

[7] Hsiao TC . 1973. Plant response to water stress. Annual Review of Plant Physiology 24, 51970

[8] Harris P M. 1978a. Mineral nutrition, pp. 196-243, In The Potato Crop, ed. P. M. Harris Chapman and Hall, London

[9] Harris PM. 1978 b. Water, pp. 244-78, In The Potato Crop, ed. P. M. Harris. Chapman and Hall, London.

[10] Wong SC, Cowan IR, Farquhar GD. 1979. Stomatal conductance correlates with photosynthesis capacity. Nature (London) 282, 424-6

[11] Kumar P, Pandey SK, Singh BP, Singh SV, Kumar D. 2007. Effect of nitrogen rate on growth, yield, economics and crisps quality of Indian potato processing cultivars. Potato Res., $50,143-155$

[12] Hughes JC. 1986. The effects of storage temperature, variety and mineral nutrition on sugar accumulation. In Aspects of Applied Biology 13, Crop Protection of Sugar Beet and Crop Protection and Quality of Potatoes, 28-33. Wellesbourne, UK: Association of Applied Biologists

[13] Chaerle L, Leinonen I, Jones HG, Van Der Straeten D, 2007. Monitoring and screening plant populations with combined thermal and chlorophyll fluorescence imaging. J. Exp. Bot. 58, 773-784

[14] Langsdorf G, Buschmann C, Sowinska M, Babani F, Mokry M, Timmermann F, Lichtenthaler HK. 2000. Multicolor fluorescence imaging of sugar beet leaves with different nitrogen status by flash lamp UV-excitation. Photosynthetica 38, 539-551

[15] Heisel F. Sowinska M. Miehe JA, Lang M, Lichtenthaler HK. 1996. Detection of nutrient deficiencies of maize by laser induced fluorescence imaging. J. Plant Physiol. 148, 622-631 
[16] Butler WL .1978. Energy distribution in the photochemical apparatus of photosynthesis. Annual Review of Plant Physiology 29, 457-478

[17] Genty B, Goulas Y, Dimon B, Peltier G, Briantais JM, Moya I . 1992. Modulation of efficiency of primary conversion in leaves, mechanisms involved at PS2. In : Murata N, ed. Research in photosynthesis, Vol. IV : Proceedings of IXth International Congress on Photosynthesis. Nagoya, Japan, August 30-September 4, 603-610

[18] Demmig B, Björkman O. 1987. Photon yield of O2 evolution and chlorophyll fluorescence characteristics at $77 \mathrm{~K}$ among vascular plants of diverse origins. Planta 170, 489-504

[19] Long SP, Humphries S, Falkowski PG. 1994. Photoinhibition of photosynthesis in nature. Annual Review of Plant Physiology and Plant Molecular Biology 45, 633-662

[20] Demmig-Adams B, William W, Adams I .2006. Photoprotection in an ecological context: the remarkable complexity of thermal energy dissipation. New Phytologist 172,11-21

[21] Baker NR. 2008. Chlorophyll fluorescence: a probe of photosynthesis in vivo. Annual Review of Plant Biology 59, 89-113

[22] Dubois M, Gilles KA, Hamilton JK, Rebers PA, Smith F. 1956. Colorimetric method for the determination of sugars and related substances. Anal. Chem. 28: 350-356

[23] Yadav, $\mathrm{R}$ et al. 2000. Yield trends, and changes in soil organic-C and available NPK in a long-term rice-wheat system under integrated use of manures and fertilisers. Field Crops Res 68, 219-246, doi:10.1016/S0378-4290(00)00126-X

[24] Guo J et al. 2010. Significant acidification in major Chinese croplands. Science 327, 10081010, doi:10.1126/science. 1182570

[25] Tilman D, Balzer C, Hill, J, Befort, BL. 2011. Global food demand and the sustainable intensification of agriculture. Proc Natl Acad Sci 108, 20260-20264, doi:10.1073/pnas.1116437108

[26] Oliveira CAS. 2000. Potato crop growth as affected by nitrogen and plant density, Pesquisa Agropecuária Brasileira, vol.35, no. 5

[27] Robredo A, Pérez-López U, Miranda-Apodaca J, Lacuesta M, Mena-Petite A, MuñozRueda A 2011. Elevated CO2 reduces the drought effect on nitrogen metabolism in barley plants during drought and subsequent recovery. Environ. Exp. Bot. 71:399-408

[28] Jin VL, Schmer MR, Wienhold BJ. 2015. Twelve years of stover removal increases soil erosion potential without impacting yield. Soil Science Society of America Journal, 79, 11691178

[29] Westermann DT. 2005. Nutritional requirements of potatoes. Am J Potato Res ; 82(4):301-7 
[30] Kleinkopf GE, Westermann DT, Dwelle RB. Dry matter production and nitrogen utilization by six potato cultivars. Agron J. 1981; 73(5):799-802.

[31] Errebhi M, Rosen CJ, Lauer FL, Martin MW, Bamberg JB. 1999. Evaluation of tuberbearing solanum species for nitrogen use efficiency and biomass partitioning. Am J Potato Res. 76(3):143-51

[32] Hopkins BG, Rosen CJ, Shiffler AK, Taysom TW. 2008. Enhanced efficiency fertilizers for improved nutrient management: potato (Solanum tuberosum). Crop Management. 7(1)

[33] Bélanger G, Walsh JR, Richards JE, Milburn PH, Ziadi N .2000. Yield response of two potato cultivars to supplemental irrigation and $\mathrm{N}$ fertilization in New Brunswick. Am J Potato Res 77:11-21

[34] Krauss A .1985. Interaction of nitrogen nutrition, phytohormones and tuberization. In PH Li, ed, Potato Physiology. Academic Press, London, pp 209-231

[35] Koda Y, Takahashi K, Kikuta Y, Greulich F, Toshima H, Ichihara A .1996. Similarities of the biological activities of coronatine and coronafacic acid to those of jasmonic acid. Phytochemistry 41: 93-96

[36] Li W, Xiong B, Wang S, Deng X, Yin L, Li H (2016) Regulation Effects of Water and Nitrogen on the Source-Sink Relationship in Potato during the Tuber Bulking Stage. PLOS ONE 11(1): e0146877. doi:10.1371/journal.pone.0146877 